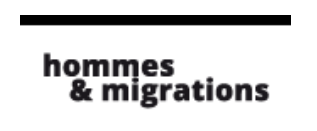

Hommes \& migrations

Revue française de référence sur les dynamiques

migratoires

1286-1287 | 2010

Les migrations subsahariennes

\title{
L'élève migrant africain au tournant des indépendances
}

Structures littéraires de l'expérience coloniale

Nicolas Treiber

\section{(2) OpenEdition}

12 Journals

\section{Édition électronique}

URL : http://journals.openedition.org/hommesmigrations/1721

DOI : 10.4000/hommesmigrations. 1721

ISSN : 2262-3353

Éditeur

Musée national de l'histoire de l'immigration

\section{Édition imprimée}

Date de publication : 1 juillet 2010

Pagination : 36-47

ISSN : $1142-852 X$

\section{Référence électronique}

Nicolas Treiber, «L'élève migrant africain au tournant des indépendances », Hommes \& migrations [En ligne], 1286-1287 | 2010, mis en ligne le 29 mai 2013, consulté le 19 avril 2019. URL : http:// journals.openedition.org/hommesmigrations/1721; DOI : 10.4000/hommesmigrations.1721 


\section{L'élève migrant africain au tournant des indépendances Structures littéraires de l'expérience coloniale}

Par Nicolas Treiber, doctorant au Centre international d'études francophones (CIEF), université de la Sorbonne (Paris IV)

Les premiers romans autobiographiques d'Afrique subsaharienne (1953-1961) ont comme point commun de mettre en scène une expérience

historiquement déterminée : l'acculturation au monde occidental de l'élève africain colonisé. À travers le voyage qui le conduit d'Afrique vers la France, l'élève africain de l'époque coloniale fait une épreuve radicale de la migration. Entraîné dans le royaume de l'hybride, l'élève migrant supporte le clivage entre deux cultures et deux identités. Décryptage de l'expérience migratoire en situation coloniale à partir de trois classiques de la littérature africaine francophone. 
Les auteurs africains d'expression française qui ont écrit et publié entre la fin de la Seconde Guerre mondiale et les indépendances ont en commun une situation historique : la situation coloniale. Leur parcours d'étudiants colonisés, partis pour la plupart achever leurs études en France au lendemain de la guerre, constitue un thème central pour de nombreux romans de cette période, qui marque l'enracinement de la littérature africaine dans le champ francophone.

C'est dans le voyage que des écrivains africains comme Camara Laye, Aké Loba ou Cheikh Hamidou Kane puisent la matière de leurs premiers romans, puisque c'est l'issue de ce voyage qui les a poussés vers l'écriture : le besoin de démêler les fils d'une expérience particulière qui scelle, dans un contexte colonial, la perte de soimême à la rencontre de l'Autre.

Lilyan Kesteloot, pionnière de l'histoire littéraire africaine, est la première à avoir suggéré une lecture homogène de "toute une série de romans autobiographiques" parus au tournant des indépendances. Selon elle, ces romans " qui décrivent les tribulations du jeune Noir - le plus souvent étudiant - qui arrive en France", le feraient d'après un schéma actanciel plus ou moins stable, suivant lequel "le héros se débat, vainc, ou est vaincu ${ }^{(1)}$ ". Réduite à sa plus simple expression logique, leur trame narrative se déploierait dans cette alternative entre victoire et défaite. Dans L'Enfant noir de Camara Laye, L'Aventure ambiguë de Cheikh Hamidou Kane et Kocoumbo, l'étudiant noir d'Aké Loba, le personnage principal est l'élève africain, le partant. En jouant sur les polarités spatio-temporelles (aller-retour) et culturelles (les représentations que le colonisé se forme d'ici et de là-bas), ces romans permettent d'atteindre, au cceur de la conscience humaine, ces zones de frictions idéologiques où se remodèlent les identités.

\section{La structure de la relation coloniale}

Il s'agit d'approfondir la nature et le fonctionnement du combat que (se) livrent les étudiants africains en France. Un combat intériorisé qui, en retour, questionne la communauté des hommes. C'est en relevant ses traces dans les romans que l'on pourra appréhender la situation culturelle de l'homme soumis à la colonisation, à l'acculturation et à l'aliénation. Et partant, de la situation du migrant dans un contexte de domination culturelle.

La polarité socio-idéologique qui sert de trame aux romans, la confrontation entre monde traditionnel et monde moderne, est déjà le produit de la situation coloniale qui présente de la modernité une image tronquée bouleversant la cohésion même du pôle traditionnel. Forgé par Balandier, ce concept de "situation coloniale" désigne la 
mise en place d'un dispositif "à la fois politique, économique, culturel et idéologique, par lequel le colonisateur va disposer de tous les secteurs de la société colonisée et en user en fonction de son propre intérêt sans que soit pris en considération, - sauf pour des besoins tactiques - celui du peuple colonisé(2)".

Ainsi, les Africains ne se trouvent pas directement à la croisée des chemins, partagés entre la culture européenne et leur propre culture. Frantz Fanon permet de mieux appréhender ce fond de déréliction culturelle qui sert de terreau aux actions des colonisés dans les romans. "Pour l'Africain la société blanche a brisé son ancien monde sans lui en donner un nouveau. [...] Elle barre la route de l'avenir après avoir fermé la porte du passé $^{(3)}$." En effet, la relation coloniale repose sur une dépossession, une expropriation fondamentale du colonisé : "Le bouleversement a atteint le Noir de l'extérieur. Le Noir a été agi ${ }^{(4)}$." Le colonisé n'est pas l'agent de sa propre histoire. Comme expérience du monde extra-colonial selon des modalités coloniales, le voyage d'études est irrémédiablement marqué par le sceau de cette passivité. Cette dernière détermine le sens que peut recouvrir l'élève migrant colonisé en littérature : il est davantage voyagé qu'il ne voyage vraiment, tant ce qu'il découvre ne correspond que trop rarement à ses attentes, tant il est à la merci de forces qui le dépassent. C'est dans la conscience progressive de sa dépendance, à travers la mise en perspective que permet le voyage, que l'élève migrant va prendre la mesure de sa situation de colonisé. C'est au niveau de l'identité à soi et de la transmission de la mémoire que se distingue le mieux ce double mouvement d'érosion de la culture traditionnelle et de cristallisation d'attentes déçues.

\section{L'école au cœur de la colonisation des esprits}

Le système colonial français s'est d'emblée servi de l'école pour pérenniser ses conquêtes. Il n'est besoin que de rappeler les intentions programmatiques que Georges Hardy, inspecteur du système scolaire en Afrique noire, formulait en 1917 : le moyen le plus sûr "pour transformer les peuples primitifs de nos colonies", "c'est de prendre l'indigène dès l'enfance, d'obtenir de lui qu'il nous fréquente assidûment et qu'il subisse nos habitudes intellectuelles et morales pendant plusieurs années de suite, en un mot, de lui ouvrir des écoles où son esprit se forme à nos intentions ${ }^{(5)}$."

La pénétration de l'école dans la société africaine traditionnelle a pour conséquences la crise de l'autorité parentale et un effondrement généralisé des valeurs. Car l'école coloniale vise d'abord les élites. L'“école des Otages" est la première à voir le jour à Saint-Louis en 1855 à l'initiative du gouverneur Faidherbe. Rebaptisée "collège des 
Fils de chefs et d'interprètes" en 1892, elle porte sa vocation dans son titre même : " $L a$ formule coloniale était : former l'indigène de façon quil soit pour l'Européen un auxiliaire efficace et dévoué(6)."

L'école coloniale s'appuie sur les chefferies traditionnelles pour, d'une part, phagocyter leur pouvoir et, d'autre part, s'assurer que l'entreprise d'acculturation commence par là où elle aura le plus d'écho dans les consciences. Le père de Camara Laye fait partie de la caste des forgerons. Cheikh Hamidou Kane présente dans son roman les hésitations de la noblesse peuhle dont il est issu à envoyer Samba Diallo - son propre surnom de jeunesse - à l'école des Blancs.

Les auteurs cités, tout comme leurs héros, ont franchi les étapes de l'école du village, de l'école urbaine, ont obtenu leur certificat d'études ouvrant la voie des Écoles normales (formation de commis, d'instituteurs ou d'aides-médecins) ou à des écoles supérieures professionnelles. S'ils ont en partie bénéficié de l'alignement de l'enseignement en $\mathrm{AOF}$ sur celui de la métropole voulu par l'Union française (créée en 1946), c'est pour mieux constater le décalage persistant des méthodes et des savoirs. Kocoumbo, le héros d'Aké Loba, titulaire du Certificat d'études primaires supérieures arrive en France dans ce contexte : il se voit obligé de recommencer sa formation en classe de quatrième, à 21 ans.

Selon Kesteloot, Kocoumbo, l'étudiant noir de l'Ivoirien Aké Loba, est le plus représentatif de ce type de romans autobiographiques centrés sur l'expérience migratoire en situation coloniale. Il joue sur les clichés relatifs aux différents espaces de l'expérience migratoire. À Kouamo, petit village sis à côté d'une zone urbaine, l'engouement pour l'école coloniale dépasse les prévisions du chef qui n'est autre que le père de Kocoumbo. S'il s'interroge sur le bien fondé du voyage des jeunes vers la France, il n'a d'autre choix que de laisser son fils suivre le mouvement. Partir pour cette France de l'après-guerre, cette France de l'Union française qui a troqué la chicote pour le paternalisme bon ton.

\section{Quand une sous-culture détermine une vision du monde}

Un trait marquant chez l'élève colonisé qu'incarne à merveille Kocoumbo, c'est justement les représentations erronées qu'il se fait de la France depuis la culture de catalogues qui cristallise ses attentes et va enraciner sa déception : "Il s'agenouilla, prit la pile de catalogues des grands magasins de Paris qui lui servait d'oreiller. [...] Il n'y avait plus que Paris dans son cceur. [...] Le jeune homme arriva ainsi à se persuader... dans l'ensemble Paris s'apprêtait à le recevoir. [...] Se considérant déjà comme un étranger, il ne 
se mêlait plus ni aux uns ni aux autres ${ }^{(7)}$." Et sa mère répond à ses illusions d'optiques : “C'étaient les livres de son enfant, les livres qui l'aidaient à comprendre la subtilité de la langue française. Elle les arrangeait chaque matin avec le même soin qu'elle accordait aux choses ancestrales, c'est-à-dire avec un respect sacré( ${ }^{(8)}$." Ainsi, dans la cale du paquebot qui les conduits vers Marseille, les élèves africains venus de toutes les régions d'Afrique de l'Ouest rêvent l'issue de leur voyage plutôt qu'ils n'en appréhendent la structure réelle: "À les entendre, il fallait deux, trois ou quatre ans d'études pour pouvoir exercer n'importe quelle profession si importante fût-elle. Tout était facile quant on était comme eux diplômé de l'enseignement primaire. [...] Ce n'était pas tant pour soigner les malades qu'on décidait de se faire médecin que pour avoir le droit de déambuler avec cette assurance et de posséder une mentalité supérieure. Lui, Kocoumbo, avait vu un avocat et il voulait être avocat ${ }^{(9)}$."

Un autre élément à retenir est la façon dont le groupe distingue le partant, le singularise et, au fond, le charge de sa survie même. Car la possibilité de mener à bien de longues études, d'accéder à une autre condition sociale sert la collectivité en fonction des logiques de solidarité. Or, il y a un décalage fondamental dans le roman d'Aké Loba entre l'importance de l'enjeu et la légèreté avec laquelle partent les élèves. Kocoumbo qui s'étourdit dans ses rêves de grandeur facile, une fois là-bas, va violemment déchanter. Dans cette désillusion programmée, on pourrait voir une des premières manifestations de la démesure, de l'hubris dont l'élève migrant va faire l'expérience radicale dans le déroulement même de son voyage.

Partir pour la France à cette époque, en endossant l'uniforme occidental magnifié du complet veston, c'est marquer sa place dans cette classe sociale forgée de toutes pièces par l'école et la société coloniale, celle des "évolués" selon le langage colonial. Au seuil du départ, comme beaucoup d'autres colonisés acculturés, l'élève est réifié dans un rapport de domination qui s'appuie sur la diffusion d'une sous-culture. Selon Bernard Mouralis : "Le choix, s'il existe, ne peut-être qu'entre une caricature de culture européenne et ce que le colonisateur a laissé subsister de la culture autochtone ${ }^{(10)}$."

Ce rapport de domination culturelle a ceci de particulier qu'il est fondé sur la nonréciprocité. Il se nourrit des attentes qu'il sait produire sans jamais les satisfaire. On est en plein dans l'expression de cette "société de provocation" que dénonçait Romain Gary à propos des émeutes raciales de Los Angeles en $1968^{(11)}$. C'est ici que Bernard Mouralis identifie le point de naissance de l'individu "déraciné". "Les intellectuels ne pensent pas souvent que ce qu'ils considèrent comme leurs acquis au contact du colonisateur ne leur est pas reconnu par celui-cit2)." Leur voyage en France cristallise cette relation clivée entre des attentes et un monde où elles ne sont pas réciproques. C'est ce qu'en France le personnage de Pierre-Louis, avocat antillais engagé dans la lutte contre la colonisation, assène avec lucidité à Samba Diallo. "L'Occident se passe 
de vous, l'on vous ignore, vous êtes inutile, et cela, quand vous ne pouvez plus vous passer de l'Occident. Alors vous faites le complexe du mal aimé, votre position est précaire ${ }^{(13)}$." Cette précarité n'est pas de circonstance. Elle serait plutôt le cceur déceptif de la relation coloniale.

\section{Les ressorts de la mise en échec}

Comment l'élite traditionnelle, confrontée au premier plan à l'acculturation en situation coloniale, est-elle conduite à envoyer ses enfants sur ce chemin où, entre la peur de décevoir et la honte d'eux-mêmes, ces derniers auront le plus grand mal à forger de nouveaux repères sans effacer les anciens?

Cheikh Hamidou Kane est allé le plus loin possible dans la compréhension de cet enjeu interne à la société africaine : y aller ou pas. Si l'on se reporte à la présentation qu'en fait Vincent Monteil, les personnages de L'Aventure ambiguë ressembleraient à ceux d'un jeu d'échecs. Question d'envergure et de possibilité d'action. Enracinés dans leurs positions, leurs mouvements sont déterminés au sein de leur aire propre entre la volonté de préserver une identité et une culture africaines et le constat de la nécessaire adaptation au mode de vie occidental que la colonisation impose aux populations sur lesquelles elle s'exerce. 
C'est le personnage de la Grande Royale, princesse peuhle des Diallobé, qui décrypte le mieux les ressorts de la colonisation dont la conséquence est l'absence même de choix. "De l'aimant, l'école tient son rayonnement. Elle est solidaire d'un ordre nouveau, comme un noyau magnétique est solidaire d'un champ. Le bouleversement de la vie des hommes à l'intérieur de cet ordre nouveau est semblable aux bouleversements de certaines lois physiques à l'intérieur d'un champ magnétique. On voit les hommes se disposer, conquis, le long de lignes de forces invisibles et impérieuses ${ }^{(14) . "}$

L'école coloniale à la fois détruit et attire, elle instaure un clivage radical au sein même de la société traditionnelle, entre l'engouement des jeunes pour la sousculture dans laquelle ils baignent et la méfiance résignée des vieux. Or, problèmes de débouchés, rêves de promotion illusoires, les promesses ne sont pas tenues. L'élève migrant concentre, intériorise cette réorganisation de lignes de forces.

L'entrée dans ce système scolaire est déjà un voyage, un éloignement, un décentrement, qui fonde la tension entre acculturation et déculturation, l'horizon de tout voyage ultérieur. Dans L'Aventure ambiguë, le chef des Diallobé pose une alternative centrale: "Si je leur dis d'aller à l'école, ils iront en masse. [...] Apprenant, ils oublieront aussi. Ce qu'ils apprendront vaut-il ce qu'ils oublieront? Je voulais vous demander: peut-on apprendre ceci sans oublier cela, et ce qu'on apprend vaut-il ce qu'on oublie ${ }^{(15)}$ ?"Ce questionnement désigne l'évaluation des gains culturels du voyage qui commence à la porte de l'école. Or on ne peut en juger qu'a posteriori. Le colonisé n'a pas le choix de se mettre ou non en jeu. À la manière du joueur de Pascal, il est embarqué, mais c'est la colonisation qui lui impose ses règles. Entre la connaissance d'un autre monde et l'oubli du sien, il y a fort à parier qu'il se perde lui-même.

\section{Le paradoxe de la survie culturelle}

D'ailleurs, la Grande Royale a conscience de sa situation paradoxale : dans ce nouvel ordre colonial, si la noblesse traditionnelle veut conserver son pouvoir, il convient qu'elle se porte en première ligne : "Il faut apprendre chez eux l'art de vaincre sans avoir raison. Au surplus le combat n'a pas cessé encore. Lécole étrangère est la forme nouvelle de la guerre que nous font ceux qui sont venus, et il faut y envoyer notre élite, en attendant d'y pousser tout le pays. Il est bon qu'une fois encore l'élite précède ${ }^{(16)}$." Lectrice avisée de l'ceuvre de Cheikh Hamidou Kane, la critique américaine Janet Patricia Little relève dans cet "art de vaincre sans avoir raison" une relation intertextuelle déterminante avec l'cuvre d'André Malraux, La Condition humaine. Ce dernier fait dire à son personnage Thiémoko: "Il ne s'agit pas d'avoir raison mais de vaincre $e^{(17) . " ~ V o i c i ~ e n ~}$ quelque sorte la clé pragmatique de l'horizon de tout progrès au sein de la modernité 
occidentale. Le héros de L'Aventure ambiguë, Samba Diallo, véritable pion à la merci de rapport de forces qui le dépassent, est engagé dans un combat où la victoire s'obtient au prix de l'intégrité humaine. Doublement agi par le nouveau monde auquel il doit se confronter et l'ordre traditionnel qui l'y pousse, il paiera de sa personne cette déconnexion interne au régime de l'action, entre pouvoir et savoir, entre les moyens et la fin. Plus que ses personnages, c'est le roman entier qui fonctionne comme un jeu d'échecs, qui est le théâtre d'une mise en échec.

La Grande Royale n'est pas dupe de l'issue même de cette aventure. Mieux, en engageant les Diallobé à envoyer leurs enfants en masse à l'école, elle leur en livre la clé paradoxale : leur survie culturelle passera par leur mort. "Lécole où je pousse nos enfants tuera en eux ce qu'aujourd'hui nous aimons et conservons avec soin, à juste titre. Peut-être notre souvenir lui-même mourra-t-il en eux. Quand ils nous reviendront de l'école, il en est qui ne nous reconnaîtront pas. Ce que je propose c'est que nous acceptions de mourir en nos enfants et que les étrangers qui nous ont défaits prennent en eux toute la place que nous aurons laissée libre ${ }^{(18)}$." La clairvoyance de ce personnage est à la hauteur du fonctionnement même de l'Histoire. Dans cette relation dialectique entre la mort et la survie culturelle, la seule façon d'échapper à cette capacité mortifère de l'Histoire est de gagner le non-lieu qu'elle ne pourra justement jamais atteindre. Michel de Certeau permet d'expliciter ce pouvoir propre de la mémoire qui s'exerce depuis un non-lieu, qui assume sa position atopique. "Le mort hante le vif. Il re-mord (morsure secrète et répétée). Aussi l'histoire est-elle 'cannibale', et la mémoire devient-elle le champ clos où s'opposent deux opérations contraires : l'oubli, qui n'est pas une passivité, une perte, mais une action contre le passé ; la trace mnémonique, qui est retour de l'oublié désormais contraint au déguisement ${ }^{(19)}$." Dans le champ de l'Histoire, la mort ou la survie d'une culture dépend de la pérennisation de sa mémoire. Le propre de l'historiographie occidentale - dans sa structure impérialiste - étant de prendre la place, de parler à la place des cultures "autres" qu'elle intègre aux marges de son récit, tout mode de survivance ne peut que se fonder sur la rémanence des traces culturelles qui échappent justement à cette logique uniformisante.

\section{Déclinaisons d’une expérience déceptive}

Dans les romans, les témoignages de désillusion rendent compte de la nature même de l'expérience migratoire en situation coloniale. Avec Kocoumbo, les attentes déçues se manifestent au niveau matériel de ses conditions de vie en France. Son expérience de Paris va à l'encontre de tous les espoirs qu'il avait échafaudés avant de partir. Kocoumbo est incapable d'aller au bout de ses études par manque d'une solide 
méthode de travail. Sa formation scolaire coloniale découvre ses faiblesses : au fond, il apprend sans comprendre. Après avoir usé des solidarités villageoises et connu la vie dans une cité d'étudiants d'Afrique noire, Kocoumbo se retrouve dans le dénuement le plus total, piégé dans une chambre de bonne misérable. "Pouvait-il prévoir qu'un jour Paris lui offrirait un tel grabat! - Quelle chambre! Paris me dégoûte! Il s'est plaint tout haut et il sait que c'est encore inutile. Ce qui frappe le plus Kocoumbo, c'est que ce réduit est moins confortable que sa case. On n'a pas idée de ça! C'est horrible, tout de même! Avoir quitté sa case pour ce comble infect, ses parents pour une concierge au visage de harpie, ses jeux et sa gaieté pour la famine et le désespoir ${ }^{(20)}$.." C'est pour lui le début d'une descente aux enfers. Kocoumbo se voit contraint d'aller travailler en usine, puis, ultime étape de sa déchéance, d'aller jouer des percussions dans un caveau de Pigalle où il est rattrapé par tous les clichés exotiques associés au musicien noir. Au pays, des photos "pornographiques" de lui en compagnie d'une chanteuse blanche circulent, ajoutant à son échec la honte collective. À la fin du roman, c'est M. Gabe, un administrateur colonial ami de son père décédé, qui lui vient en aide en lui offrant une dernière chance de mener à bien ses études. Ce dernier retournement n'efface

Chez Cheikh Hamidou Kane, l'expérience de la déchéance s'élabore autour d'une perte progressive des repères culturels et idéologiques, c'est-à-dire une perte radicale de la mémoire. L'Aventure ambiguë peut être lue comme une mise en scène de la déréliction du personnage. en rien le contenu d'un voyage dont l'issue n'est rendue heureuse que par l'intervention d'un représentant de l'ordre colonial.

On a pu voir dans L'Enfant noir de Camara Laye, une fresque passéiste décrivant par le menu une culture traditionnelle moribonde. Ce fut le cas, en son temps, de Mongo Béti : son article Afrique noire, littérature rose ${ }^{(21)}$ épinglait Camara Laye au motif que son roman ne répondait pas aux exigences des combats anticolonialistes de l'époque. Ce roman, écrit depuis la France par un migrant, achève sa narration au seuil du départ du héros. S'il est nostalgique certes, il dit bien autre chose. Au-delà des données ethnographiques sur les rites d'initiation et sur la vie quotidienne des Malinké en Guinée perce un témoignage lucide sur l'oubli progressif du savoir traditionnel chez le héros : la mise en scène de sa propre déculturation. "Cet usage, comme tous nos usages, devait avoir sa raison, [...] mais je n'avais pas l'âge alors ni la curiosité d'interroger les vieillards, et quand enfin jai atteint cet âge, je n'étais plus en Afrique ${ }^{(22) . " ~ C ' e s t ~ l a ~}$ conséquence fondamentale de son passage par l'école coloniale, puis de son départ pour la France. "Le monde bouge, le monde change; il bouge et change à telle enseigne que mon propre totem - jai mon totem aussi - m'est inconnu ${ }^{233}$." Eloigné de la transmission 
profonde de sa culture par l'école et le voyage, le héros de Camara Laye rend compte de la situation déceptive dans laquelle se trouve l'élève-migrant colonisé : ce qu'il apprend recouvre, mais ne remplace pas ce qu'il oublie. L'acculturation, fondée sur un processus d'intériorisation progressive, dévoile sa conséquence mortifère: l'instauration d'une béance au cceur de l'esprit colonisé.

\section{Expérience migratoire et déréliction}

Chez Cheikh Hamidou Kane, l'expérience de la déchéance s'élabore autour d'une perte progressive des repères culturels et idéologiques, c'est-à-dire une perte radicale de la mémoire. L'Aventure ambiguë peut être lue comme une mise en scène de la déréliction du personnage.

En choisissant de faire des études de philosophie à Paris, Samba Diallo a conscience de s'être engagé dans "litinéraire le plus susceptible de [le] perdre". Les Diallobé plaçaient tous leurs espoirs en lui, cet enfant en qui vibrait l'essence de la foi musulmane, ce jeune adolescent façonné par la culture peuhle traditionnelle en qui résonnait l'identité de son peuple, cet être enraciné dans le pays des Diallobé qui était véritablement de la trempe de ses pères. Or, durant son aventure parisienne, alors qu'il ne peut plus revenir en arrière, qu'il se sent de plus en plus coupé des racines de sa foi, qu'il ne retrouve plus le "chemin de [ce] monde", Samba Diallo résume ainsi son expérience particulière de l'Autre: "Il arrive que nous soyons capturés au bout de notre itinéraire, vaincus par notre aventure même. Il nous apparaît soudain que, tout au long de notre cheminement nous n'avons pas cessé de nous métamorphoser, et que nous voilà devenus autres. Quelques fois, la métamorphose ne s'achève pas, elle nous installe dans l'hybride et nous y laisse. Alors nous nous cachons, remplis de honte ${ }^{(24)}$." Samba Diallo représente un double échec : celui de la colonisation qui ne parvient pas à reconfigurer complètement l'être en fonction de ses intérêts, celui de la culture traditionnelle, qui n'offre pas toujours un pôle de résistance efficace.

Le roman souligne en effet le caractère inextricable du problème de la sélection culturelle en situation coloniale. Dans ce contexte, en tant qu'être déraciné, l'élève migrant supporte la violence de l'hybride. En présentant l'impasse que constitue cet entre-deux culturel pour son personnage, Cheikh Hamidou Kane dévoile la conséquence fatale de l'aventure coloniale : l'impossibilité structurelle du choix en matière culturelle. Confronté à la perte de lui-même, la seule alternative pour le colonisé réside dans sa capacité à assumer la non-réciprocité dans laquelle Frantz Fanon ou Bernard Mouralis décelaient la structure même de la colonisation culturelle. Au fond, et c'est le parti pris pragmatique d'un des personnages de L'Aventure 
ambiguë: "Du moment que l'Occident accepte de donner, qu'importe s'il refuse de prendre $^{(25)}$." Or c'est cette attitude qui paraît impossible à Samba Diallo "autrement qu'en théorie". Sa prise de conscience constitue le summum déceptif de son aventure, partagée in fine par tout migrant en situation de domination culturelle : "Je ne suis pas un pays des Diallobé distinct, face à un Occident distinct, et appréciant d'une tête froide ce que je puis lui prendre et ce qu'il faut que je lui laisse en contrepartie. Je suis devenu les deux. Il n'y a pas une tête lucide entre deux termes d'un choix. Il y a une nature étrange en détresse de nêtre pas deux ${ }^{(26)}$." La mise en tension des cultures diallobé et occidentale se traduit par l'impossibilité de la sélection positive de leurs apports culturels respectifs dans la mesure où leur rencontre, leur conflit ont été déterminés par la colonisation.

\section{Conclusion}

L'enfant noir n'est pas allé au bout de son initiation, tout comme Samba Diallo engagé dans l'itinéraire le plus susceptible de le perdre - la philosophie occidentale - et qui ne retrouve plus le chemin de son monde intérieur, ou encore Kocoumbo qui connaît la déchéance d'une vie exilée et sans repères... Ces trois romans ont un point commun : en plaçant l'élève migrant en situation coloniale au carrefour de deux cultures, en soulignant l'aporie de cette situation et l'impossibilité de leur unité, ils interrogent la colonisation comme réalité historique et soulignent les ressorts de la déculturation qui s'exerce au premier plan sur l'identité et la mémoire.

Le mot de la fin revient au Chevalier de L'Aventure ambiguë, le père de Cheikh Hamidou Kane, qui a su "tirer de l'Occident l'essentiel de sa culture. [...] Il savait ce qu'il y avait d'essentiel et d'important là-dedans et il savait en même temps écarter ce qui était accessoire $^{(27)}$. La sélection culturelle n'est en soi pas impossible mais elle est rendue plus que difficile par un trait particulier de la culture occidentale, qui redouble et renforce sa propension colonisatrice : "L'Occident est possédé et le monde s'occidentalise. Loin que les hommes résistent, le temps qu'il faut à la folie de l'Occident, loin qu'ils se dérobent au délire d'occidentalisation, le temps qu'il faut, pour trier et choisir, assimiler ou rejeter, on les voit au contraire sous toutes les latitudes, trembler de convoitise, puis se métamorphoser en l'espace d'une génération, sous l'action de ce nouveau mal des ardents que l'Occident répand ${ }^{28)}$." La structuration déceptive de la situation coloniale est renvoyée au cceur même de l'Occident dont l'attrait repose sur une relation circulaire et passive. Ce "mal des ardents", par lequel on désignait dès le X $\mathrm{X}^{\mathrm{e}}$ siècle les intoxications collectives de populations ayant ingéré des farines contaminées à l'ergot de seigle, se transmet désormais à l'échelle de la "société de provocation". En cherchant à ramener l'Autre dans son sillage, l'Occident ne fait que témoigner de son absence de liberté face à ses propres créations qu'il s'emploie à diffuser à l'échelle du monde entier. 


\section{Notes}

1. Lilyan Kesteloot, Les Écrivains noirs de langue française : naissance d'une littérature, Bruxelles, Éditions de l'université de Bruxelles, 1977,[1963], p. 307, note 57.

2. Bernard Mouralis, Littérature et développement, Paris, Éditions Silex, 1984, p. 52.

3. Frantz Fanon, Peau noire, masques blancs, Seuil, coll. Points, 1971, [1952], p. 149.

4. Idem, p. 178.

5. Georges Hardy, Une conquête morale - l'enseignement en AOF, Paris, L'Harmattan, 2005, [Armand Colin, 1917], pp. 6-7.

6. Jean Capelle, L'Éducation en Afrique noire à la veille des Indépendances (1946-1958), Paris, Éditions Karthala et ACCT, 1990, p. 35.

7. Aké Loba, Kocoumbo, l'étudiant noir, Paris, Flammarion, 1960, pp. 32-33.

8. Idem, p. 31 .

9. Idem, pp. 56-57.

10. Bernard Mouralis, Littérature et développement, op. cit., p. 54.

11. Romain Gary, Chien blanc, Paris, Gallimard, 1972 , pp. 97-99.

12. Lamine Diakhité, Présence africaine, $n^{\circ} 56$, cité par B. Mouralis, op. cit., p. 42.

13. Cheikh Hamidou Kane, L'Aventure ambiguë, Paris, Julliard, 1971 [1961], p. 163.

14. Idem, pp. 60-61.

15. Idem, p. 44.

16. Idem, p. 47.

17. Cité par Janet Patricia Little, Cheikh Hamidou Kane, L'Aventure ambiguë, Grant \& Cutler Ltd, 2000, p. 66.

18. Cheikh Hamidou Kane, L'Aventure ambiguë, op. cit., p. 57.

19. Michel de Certeau, Histoire et psychanalyse - Entre science et fiction, Paris, Gallimard, 2002 [1987], p. 85.

20. Aké Loba, Kocoumbo, l'étudiant noir, op. cit., p. 216.

21. Mongo Béti, "Afrique noire, littérature rose", in Présence africaine, $n^{\circ} 1-2$, avril-juillet 1955, pp. 133-140.

22. Camara Laye, L'Enfant noir, Paris, Plon, 1953, p. 56.

23. Idem, p. 80 .

24. Cheikh Hamidou Kane, L'Aventure ambiguë, op. cit., p. 125.

25. Idem, p. 164.

26. Ibidem.

27. Entretien avec Maryse Condé, Radio France internationale, Paris, Clef, 1979.

28. Cheikh Hamidou Kane, L'Aventure ambiguë, op. cit., p. 81. 